УДК 338.2

ББК 65.050

СИНТЕТИЧЕСКАЯ МОДЕЛЬ НАЦИОНАЛЬНОЙ ЭКОНОМИЧЕСКОЙ СИСТЕМЫ РЕСПУБЛИКИ БЕЛАРУСЬ НА ОСНОВЕ МОДИФИЦИРОВАННЫХ ТАБЛИЦ «ЗАТРАТЫ-ВЫПУСК»

\author{
А. И. КОРОТКЕВИЧ \\ alexeyk75@mail.ru \\ кандидат экономических наук, доцент, \\ заведующий кафедрой банковской экономики \\ Белорусский государственный университет \\ Минск, Республика Беларусь
}

В статье разработана синтетическая модель национальной экономической системы на основе модификачии таблии «Затраты-Выпуск», использование которой позволит проводить прогнозирование и планирование развития страны на уровне видов экономической деятельности, обосновано подходить к формированию сценариев трансформации экономики и количественно оценивать последствия принимаемых в этом отношении решений.

Ключевые слова: национальная экономическая система, модель Леонтьева, таблицы «Затраты-Выпуск», виды экономической деятельности, импорт, экспорт, работники, группы занятий

\title{
SYNTHETIC MODEL OF THE NATIONAL ECONOMIC SYSTEM OF THE REPUBLIC OF BELARUS BASED ON MODIFIED TABLES "COSTS-OUTPUT"
}

\author{
A. I. KOROTKEVICH \\ $\mathrm{PhD}$ in Economics, Associate Professor \\ the Head of the department of Banking Economics \\ Belarusian State University \\ Minsk, Republic of Belarus
}

The article has developed a synthetic model of national economic system on the basis of modification of tables "cost Issue", which will allow for forecasting and planning for the development of the country at the level of economic activities, grounded approach to the formation of transformation scenarios and quantify the impact of decisions in this regard.

Key words: the national economic system, model leontiev, input-output table, economic activities, import, export, workers, group lessons.

\section{ВВЕДЕНИЕ}

Современный этап социально-экономического развития Республики Беларусь характеризуется формированием модели национальной экономической системы, системообразующим блоком функционирования которой, в соответствии с Национальной стратегией устойчивого социально-экономического развития Республики Беларусь на период 2030 года, должно стать социально ориентированное, экономически эффективное и экологозащитное развитие страны с учетом удовлетворения потребностей нынешних и будущих поколений. При этом стратегической целью устойчивого развития Республики Беларусь является обеспечение высоких жизненных стандартов населения 
и условий для гармоничного развития личности на основе перехода к высокоэффективной экономике, базирующейся на знаниях и инновациях, при сохранении благоприятной окружающей среды для будущих поколений. Достижение поставленной стратегической цели требует обоснования и реализации соответствующих решений по дальнейшему совершенствованию структуры национальной экономической системы Республики Беларусь и повышению эффективности ее функционирования. С учетом того, что на данном уровне управления экономикой особенно сложно предусмотреть умозрительно все возможные последствия предлагаемых решений, которые могут быть и масштабными, и нежелательными, необходима их проверка, которая должна делаться не только на основе экспертных прогнозов, как традиционно это происходит в Республике Беларусь, но и при помощи математических моделей. Речь идет о так называемой априорная верификация решений [1].

\section{РЕЗУЛЬТАТЫ И ИХ ОБСУЖДЕНИЕ}

Для количественной оценки результатов реализации сценариев структурной трансформации НЭС Республики Беларусь в настоящей работе разработана «Синтетическая модель НЭС на основе модификации таблиц «Затраты-Выпуск», включающая в себя ранее предложенные автором варианты модификации [2-5] модели Леонтьева [6].

Одним из важнейших качеств модели Леонтьева является возможность определения полных затрат ресурсов каждого ВЭД при заданном значении элементов вектора $Y$ путем решения относительно $X$ уравнения (1):

$$
X=(E-A)^{-1} \times Y
$$

Но таким образом полные затраты на производимые экономическими субъектами продукты можно определить только для тех экономических субъектов, которые включены в матрицу $A$, т.е. представлены видами экономической деятельности (ВЭД). Так, например, в силу отсутствия в матрице $A$ деятельности домашних хозяйств (ДХ) по представлению рабочей силы другим ВЭД, становиться невозможным определить полные затраты труда каждой группы занятий, необходимые для производства экономическими субъектами заданных объемов конечного продукта.

Для решения обозначенной проблемы в работах [2-4] предлагается включить в состав ВЭД деятельность ДХ по представлению рабочей силы другим ВЭД. В предлагаемой модели вводится $k$ видов деятельности ДХ по представлению рабочей силы работников $k$ групп занятий, классификация которых представлена ниже в соответствии ОКРБ006-2009 ОКПД [7] (ОКПД):

1. Группа занятий «Законодатели, руководители органов государственного управления, общественных организаций (объединений), коммерческих и некоммерческих организаций».

2. Группа занятий «Специалисты-профессионалы». В этой группе выделим подгруппы инженеры с кодами 2111 - 2149 (код по ОКПД).

3. Группа занятий «Специалисты».

4. Группа занятий «Работники, занятые подготовкой и обработкой информации, учетом и предоставлением услуг потребителям».

5. Группа занятий «Работники сферы обслуживания, торговли и родственных видов деятельности».

6. Группа занятий «Квалифицированные рабочие сельского, лесного хозяйств, рыболовства и рыбоводства». 
7. Группа занятий «Квалифицированные рабочие промышленности, строительства и рабочие родственных профессий (за исключением работников, вошедших в основную группу 8)».

8. Группа занятий «Операторы, аппаратчики, машинисты установок и машин, сборщики изделий».

9. Группа занятий «Неквалифицированные рабочие».

Кроме этого включается еще один вид деятельности - деятельность предпринимателей, результаты которой оцениваются размерами прибыли. При этом, в число предпринимателей включаются все владельцы коммерческих организаций - как физические, так и юридические лица, но только предприниматели физические лица участвуют в промежуточном потреблении конечного продукта как члены домашних хозяйств. Деятельность ДХ оценивается оплатой труда представленных каждому ВЭД работниками. Таким образом, к $n$ ВЭД добавляется еще $k+1$ ВЭД, где $k$-это число групп работников.

Разработанная модель содержит следующие элементы [2-4]:

1) производственную функцию;

2) матрицу коэффициентов прямых затрат;

3) матрицу производства продуктов;

4) матрицу производства и распределения ресурсов (аналог матрицы «ЗатратыВыпуск» в модели Леонтьева);

5) таблицу работников по группам занятий;

6) таблицу зарплат по группам занятий;

7) таблицу структуры распределения доходов.

Таким образом, рассматривающая в основном процесс производства и связанное с ним потребление промежуточной продукции, модель Леонтьева в результате модификации была дополнена включением в качестве эндогенных переменных работников различных групп занятий и функции потребления, что позволило создать полноценную модель НЭС. Графически основная часть разработанной модели представлена в таблице 1. 


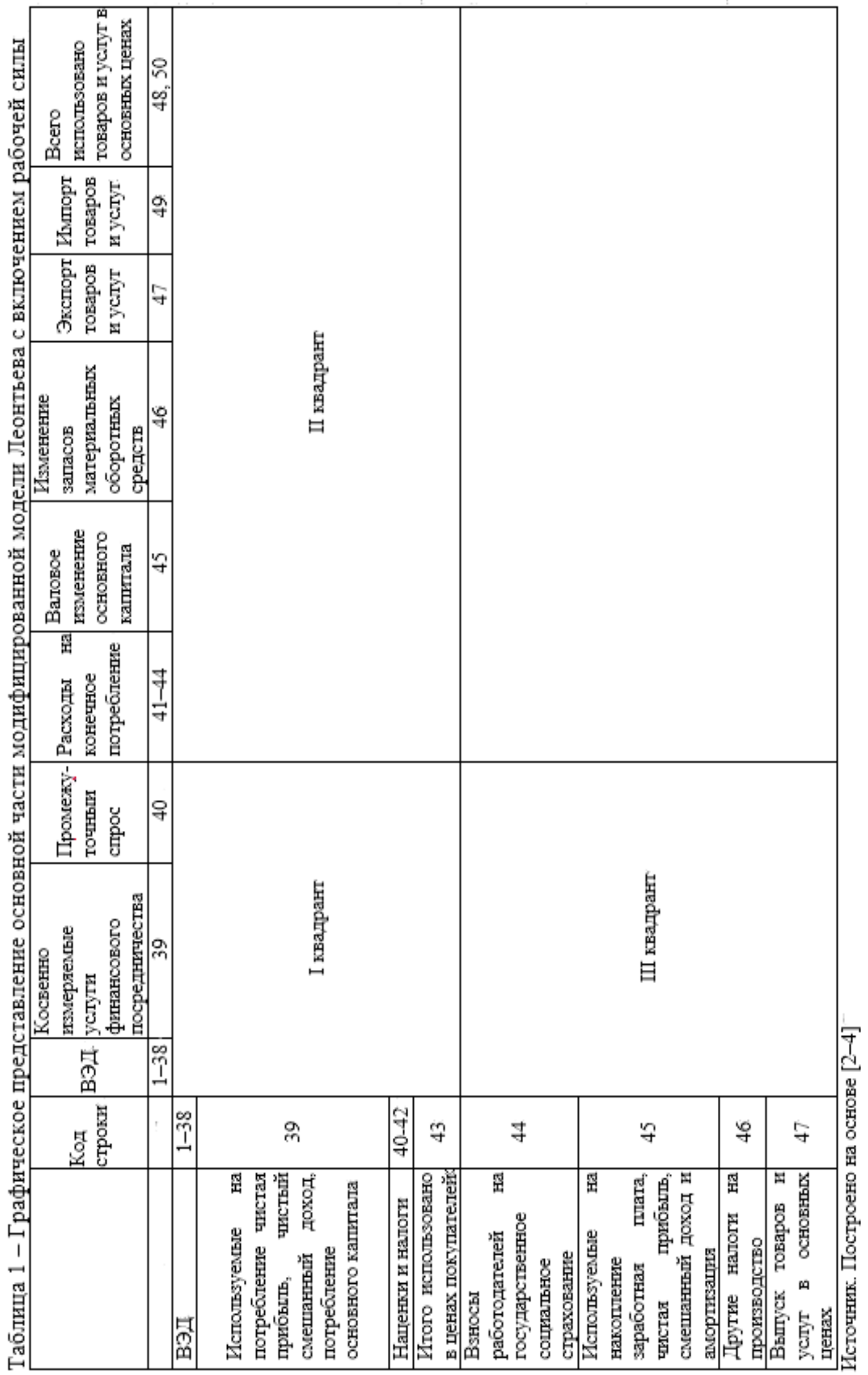


Основное отличие разработанной модели, графическое представление основной части которой представлено в таблице 1, заключается во включение в состав ВЭД услуг домашних хозяйств по представлению работников различных групп занятий, получающих за это доходы и потребляющих продукты различных ВЭД. При этом их потребление определяется функцией потребления, имеющей матричное представление. Данная функция выражает зависимость потребления работниками различных групп занятий продуктов каждого ВЭД от получаемого этими работниками доходов.

Для определения полных затрат импорта не только на экспорт, но и на любой другой вид конечного продукта, была разработана модифицированная модель Леонтьева с включением в нее импортной деятельности (ИД) для определения и планирования полных затрат импорта на экспортную продукцию. Подобная модификация системы таблиц «Затраты-Выпуск» позволила включить денежные потоки по импорту в состав промежуточных расходов [5].

Таким образом, для определения полных затрат импорта не только на экспорт, но и на любой другой вид конечного продукта, модель Леонтьева была модифицирована так, чтобы потребление импорта и затраты на него явно вошли в матрицу «Затраты Выпуск». При таком подходе к модификации указанной модели стало возможным определять прямые затраты импорта на производство продуктов для каждого ВЭД и коэффициенты полных затрат импорта, которые показывают объемы импорта, потребляемые всеми ВЭД для выпуска единицы конечной продукции каждого ВЭД, в том числе и единицы продукции экспорта. Для определения и планирования полных затрат импорта на экспортируемую продукцию в Республике Беларусь была модифицирована систему таблиц «Затраты - Выпуск», ежегодно составляемая Национальным статистическим комитетом Республики Беларусь.

В случае, если необходимо определить полные затраты импорта на конечный и итоговый продукты, то следует разработать объединяющую модель, включающую две указанные выше модели:

- модифицированную модель Леонтьева с включением рабочей силы;

- модифицированную модель Леонтьева с включением в нее импортной деятельности для определения и планирования полных затрат импорта на экспортную продукцию.

Полученная в результате такого объединения двух вышеуказанных модифицированных моделей синтетическая модель, для которой введем название «Синтетическая модель НЭС на основе модификации таблиц «Затраты-Выпуск», графически представлена в таблице 2 . 


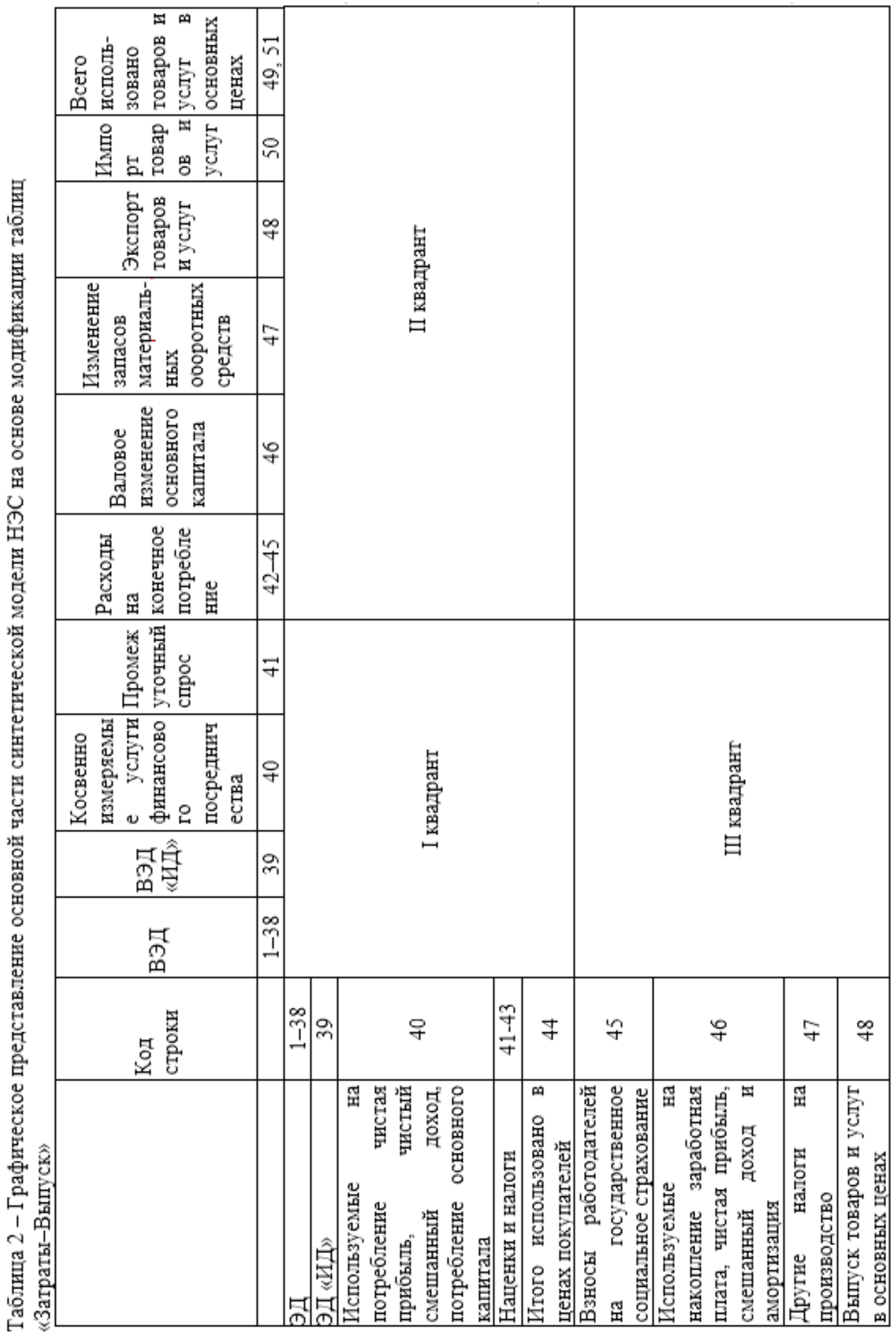


Основное преимущество представленной в таблице 2 синтетической модели НЭС на основе модификации таблиц «Затраты-Выпуск» по сравнению с указанными выше модифицированными моделями Леонтьева (с введенными в первую из них рабочей силы [2-4] и импортной деятельности во вторую модель [5]), заключается во включении в состав полных затрат импорта различных ВЭД потребление импорта работниками этих ВЭД. Это позволяет точнее определять как полные затраты импорта на производство конечного продукта каждым ВЭД, так и полные затраты импорта на итоговый продукт, т. е. на продукты, приобретаемые за счет трансфертов ДХ, расходы государства и расходы некоммерческих организаций, а также на изменение основного капитала, изменение запасов и на чистый экспорт.

\section{ВЫВОДЫ}

Для точного определения как полных затрат импорта на производство конечного продукта каждым видом экономической деятельности, так и полных затраты импорта на итоговый продукт предложена синтетическая модель национальной экономической системы на основе модификации таблиц «Затраты-Выпуск». Указанная модель объединяет в себе модифицированные модели Леонтьева с включением рабочей силы по группам занятий и с включением импортной деятельности. Указанные преобразования системы таблиц «Затраты-Выпуск» обеспечивают возможность создания полноценной модели национальной экономической системы Республики Беларусь, использование которой позволит проводить прогнозирование и планирование ее развития на уровне видов экономической деятельности, обосновано подходить к формированию сценариев трансформации экономики страны и количественно оценивать последствия принимаемых в этом отношении решений.

\section{СПИСОК ИСПОЛЬЗОВАННЫХ ИСТОЧНИКОВ}

1. Государственная экономическая политика и Экономическая доктрина России. К умной и нравственной экономике. Под общей редакцией С. С. Сулакшина. В 5 т. Т. І. М.: Научный эксперт, 2008. - 840 с. (с.40).

2. Короткевич, А. И. Моделирование национальной экономической системы Беларуси и направления ее трансформации / А.И. Короткевич // Экономика и управление: проблемы, решения, 2017 - № 6, том 3 (66) - С. 83-94.

3. Короткевич, А. И. Моделирование национальной экономической системы Беларуси и направления ее трансформации / А. И. Короткевич, Б. В. Лапко, Д.В. Шпарун // Журнал Белорусского государственного университета. Экономика, 2017 - № 1 C. $126-135$.

4. Короткевич, А. И., Лапко, Б. В., Шпарун, Д. В. Разработка модели национальной экономической системы Беларуси / Материалы 3-й международной научной конференции «Беларусь 2030: государство, бизнес, наука, образование, 27 октября 2016 г. / науч.-ред. совет : М. М. Ковалев [и др.] ; Белорус. гос. ун-т - Минск : Изд. Центр БГУ, 2016. - C. 21-31.

5. Короткевич, А. И., Лапко, Б. В. Модификация модели «Затраты-Выпуск» для определения и планирования полных затрат импорта на экспортную продукцию/ А. И. Короткевич, Б. В. Лапко // Белорусский экономический журнал. - 2015. - № 4. C. $113-125$.

6. Леонтьев, В. В. Избранные произведения: в 3 т. / В. В. Леонтьев; науч. ред., вступ. статья А. Г. Гранберга. - М.: ЗАО «Издательство «Экономика», 2006-2007. 
7. Общегосударственный классификатор Республики Беларусь ОКРБ 006-2009 «Профессии рабочих и должности служащих»: утв. постановлением Министерством труда и социальной защиты Республики Беларусь от 22 октября 2009 г. № 125 (с изменениями и дополнениями). - Минск: Министерством труда и социальной защиты Республики Беларусь, 2009 - 424 с.

\section{REFERENCES}

1. Gosudarstvennaya ekonomicheskaya politika i Ekonomicheskaya doktrina Ros-sii. K umnoy i nravstvennoy ekonomike. Pod obshchey redaktsiyey S. S. Sulakshina. V 5 t. T. I. M.: Nauchnyy ekspert. 2008. - 840 s. (s.40).

2. Korotkevich, A. I. Modelirovaniye natsionalnoy ekonomicheskoy sistemy Belarusi i napravleniya eye transformatsii / A.I. Korotkevich // Ekonomika i upravle-niye: problemy. resheniya. 2017 - № 6. tom 3 (66) - S. 83-94.

3. Korotkevich, A. I. Modelirovaniye natsionalnoy ekonomicheskoy sistemy Belarusi i napravleniya eye transformatsii / A. I. Korotkevich. B. V. Lapko. D. V. Shpa-run // Zhurnal Belorusskogo gosudarstvennogo universiteta. Ekonomika. 2017 - № 1 - S. 126-135.

4. Korotkevich, A. I., Lapko, B. V., Shparun. D. V. Razrabotka modeli natsio-nalnoy ekonomicheskoy sistemy Belarusi / Materialy 3-y mezhdunarodnoy nauchnoy konferentsii «Belarus 2030: gosudarstvo. biznes. nauka. obrazovaniye. 27 oktyabrya 2016 g. / nauch.-red. sovet : M. M. Kovalev [i dr.] ; Belorus. gos. un-t - Minsk : Izd. Tsentr BGU. 2016. - S. 21-31.

5. Korotkevich, A. I., Lapko, B. V. Modifikatsiya modeli «Zatraty-Vypusk» dlya opredeleniya i planirovaniya polnykh zatrat importa na eksportnuyu produktsiyu/ A. I. Korotkevich. B. V. Lapko // Belorusskiy ekonomicheskiy zhurnal. - 2015. - № 4. - S. 113-125.

6. Leontyev, V. V. Izbrannyye proizvedeniya: v 3 t. / V. V. Leontyev; nauch. red.. vstup. statia A. G. Granberga. - M.: ZAO «Izdatelstvo «Ekonomika». 2006-2007.

7. Obshchegosudarstvennyy klassifikator Respubliki Belarus OKRB 006-2009 «Professii rabochikh i dolzhnosti sluzhashchikh»: utv. postanovleniyem Ministerstvom truda i sotsialnoy zashchity Respubliki Belarus ot 22 oktyabrya 2009 g. № 125 (s izme-neniyami i dopolneniyami). - Minsk: Ministerstvom truda i sotsialnoy zashchity Res-publiki Belarus. $2009-424 \mathrm{~s}$.

Статья поступила в редакцию 11 ноября 2017 года. 